\title{
Effects of Forming Parameters on Fatigue Life in Incremental Sheet Punching
}

\author{
Jin Wang *, Xu Wang, Yongqiang Wang and Mengting Wang
}

check for

updates

Citation: Wang, J.; Wang, X.; Wang,

Y.; Wang, M. Effects of Forming

Parameters on Fatigue Life in

Incremental Sheet Punching.

Materials 2021, 14, 2308. https://

doi.org/10.3390/ma14092308

Academic Editor: Francesco Iacoviello

Received: 18 March 2021

Accepted: 25 April 2021

Published: 29 April 2021

Publisher's Note: MDPI stays neutral with regard to jurisdictional claims in published maps and institutional affiliations.

Copyright: (C) 2021 by the authors. Licensee MDPI, Basel, Switzerland. This article is an open access article distributed under the terms and conditions of the Creative Commons Attribution (CC BY) license (https:/ / creativecommons.org/licenses/by/ $4.0 /)$.
School of Mechanical and Automotive Engineering, Qingdao University of Technology, Qingdao 266525, China; wangxu523@126.com (X.W.); wyq199410042021@163.com (Y.W.); wangmengting618@163.com (M.W.)

* Correspondence: jinwangqtech@163.com

\begin{abstract}
In order to investigate the effects of main forming parameters on the fatigue life in incremental sheet punching, wavelength and amplitude were selected as factors, and fatigue life of truncated pyramids and virgin material was selected as indicator. The effects of the parameters were identified whereby the design of full factorial experiment, fatigue comparative test, analysis of variance, Tukey test, and $t$-test. It was found that wavelength and amplitude significantly affect the fatigue life. In addition, the improvement of fatigue life decreased with the increment of wavelength and increased with the increment of amplitude when it is less than a certain value, followed by decreasing.
\end{abstract}

Keywords: incremental sheet punching; fatigue comparative test; analysis of variance; Tukey test; $t$-test

\section{Introduction}

Incremental sheet forming (ISF) is a promising process technology for sheet metal in industry. ISF can complete the forming of parts at the ordinary Computerized Numerical Control (CNC) machine as well as special incremental forming machines with the help of the CAD model of the forming parts. Many advantages of ISF, e.g., without requirement for die or partial die, the cost is small and the forming cycle is short, flexibility for small batch sheet products, have been presented in detail by a lot of researchers. In recent years, this approach has been widely concerned and studied in the application fields of sheet metal products such as aviation, automobile, and medical treatment [1-4].

Compared to conventional ISF, incremental sheet punching (ISP) of discontinued contact between forming tool and sheet metal in forming, has the advantages of higher sheet formability, lower forming force, and suitable for forming perforated sheet, which has attracted more attention in recent years. Schafe et al. [5] designed an ISP system by combining industrial robots with hammering devices. In this forming process, the tool path was controlled by the robot program, and the reciprocating motion in the direction perpendicular to the sheet metal was controlled by the high-frequency hammering device. Based on the system, Vihtonen [6] believed that the ISP can reduce the forming force and is applicability for forming perforated sheet. Luo et al. $[7,8]$ developed a new ISP machine, based on the principle that the forming tool is fixed on the slider driven by the hydraulic cylinder, the tool driven by the hydraulic cylinder moves in the vertical direction of the sheet, and the horizontal movement of the sheet is controlled by the workbench. Sedighi et al. [9] designed an ISP mechanism camshaft, in which the cam mechanism was used to control the reciprocating motion owith af the forming tool perpendicular to the sheet, while the horizontal movement of the sheet was also controlled by the workbench. The calculation model of the pressure and velocity field of the ISP was derived by using the slip phenomenon and the upper bound method. Although ISP has many advantages, there are many problems such as low forming accuracy, long forming time, and the need for special equipment assistance, still need to be solved. Hence, multiple authors are seeking to select an reasonable process parameters to optimize ISP. ISP can reduce torsion and springback, as described by Schafer [5], who developed a method 
to generate the tool paths based on CAD model, using this method to form concave and convex parts.Wang et al. $[10,11]$ proposed an approach, which can transform the tool paths of continuous contact in traditional ISF into sinusoidal wave tool paths perpendicular to the direction of sheet metal, as illustrated in Figure 1. And in this process ISP are allowed to achieved on ISF machine without adding any additional devices. Jiang et al. [12] studied the influence of main process parameters on forming time in incremental sheet punching driven by wave tool path using the design of experiment of orthogonal array, analysis of range, and analysis of variance. The results showed that the forming time is decreased with increasing tool vertical step, feed rate, wavelength, and tool diameter, but increased with increasing amplitude.

Fracture is one of the most important failure modes in mechanical parts and engineering components, since more than $80 \%$ of fracture accidents are caused by fatigue. Therefore, it is essential to experimentally evaluate the fatigue performance of ISF parts and introduce fatigue strength design to improve the fatigue life of parts in the design. She et al. [13] studied the residual stress of the truncated cone and found that the single-point incremental forming could improve the fatigue strength of sheet. Agrawal et al. [14] formed $90^{\circ}$ bending parts by conventional bending, Single point incremental forming (SPIF), and the deformation machining process, and studied the effects of three processes on the fatigue life of parts through low cycles fatigue life test, which showed that SPIF parts had a longer fatigue life than those produced by deformation machining and conventional bending. Xu et al. [15] examine the fatigue life of parts formed employing accumulative-double-sided incremental forming (ADSIF) process, on AA2024-T3 sheets. The results indicate that the extrusion effect of the two tools on the both sides of the plate could lead to a more uniform distribution of residual compressive stress along the member wall, and therefor improving the fatigue life of the plate.

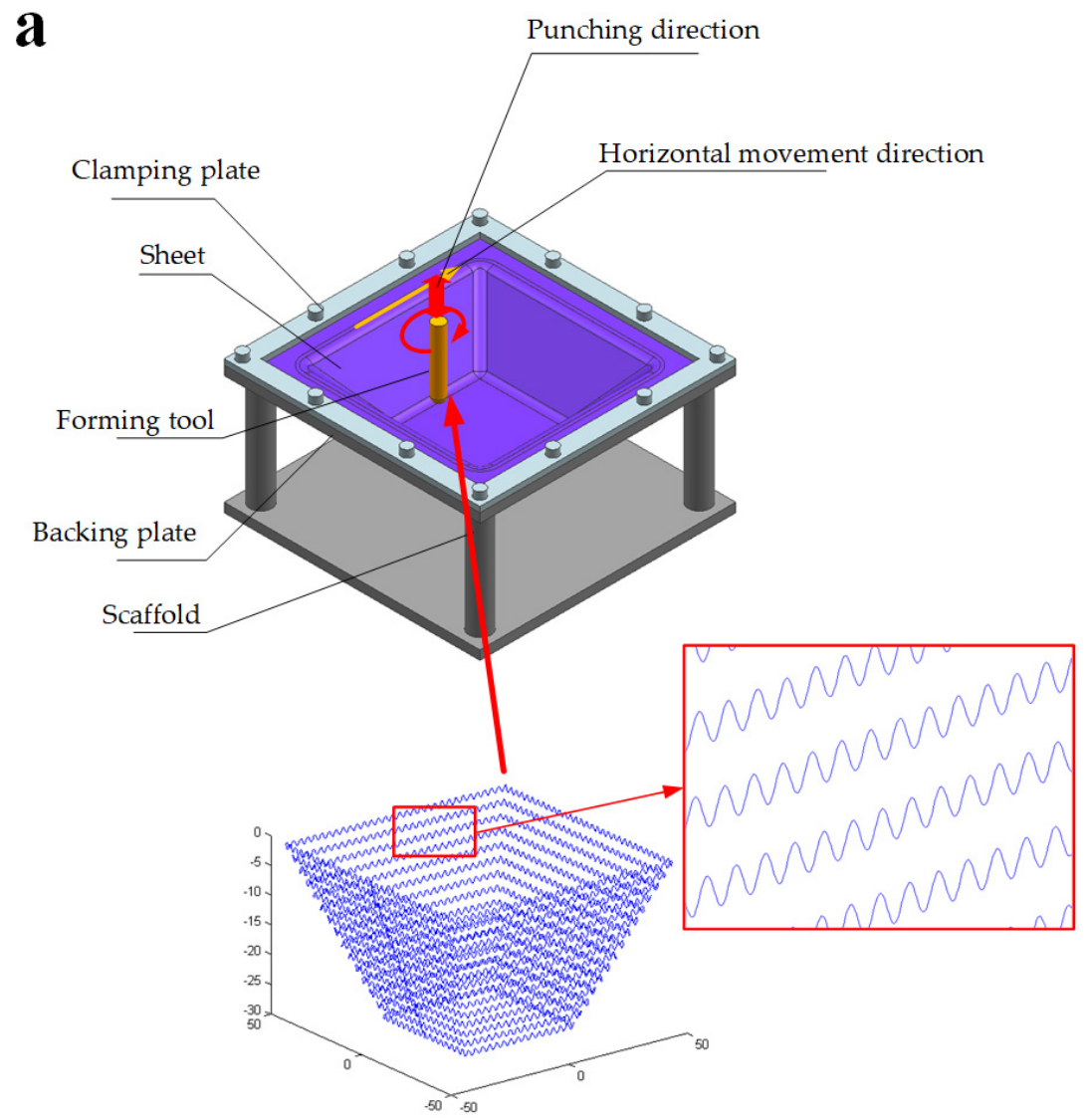

Figure 1. Cont. 
b

Horizontal movement direction

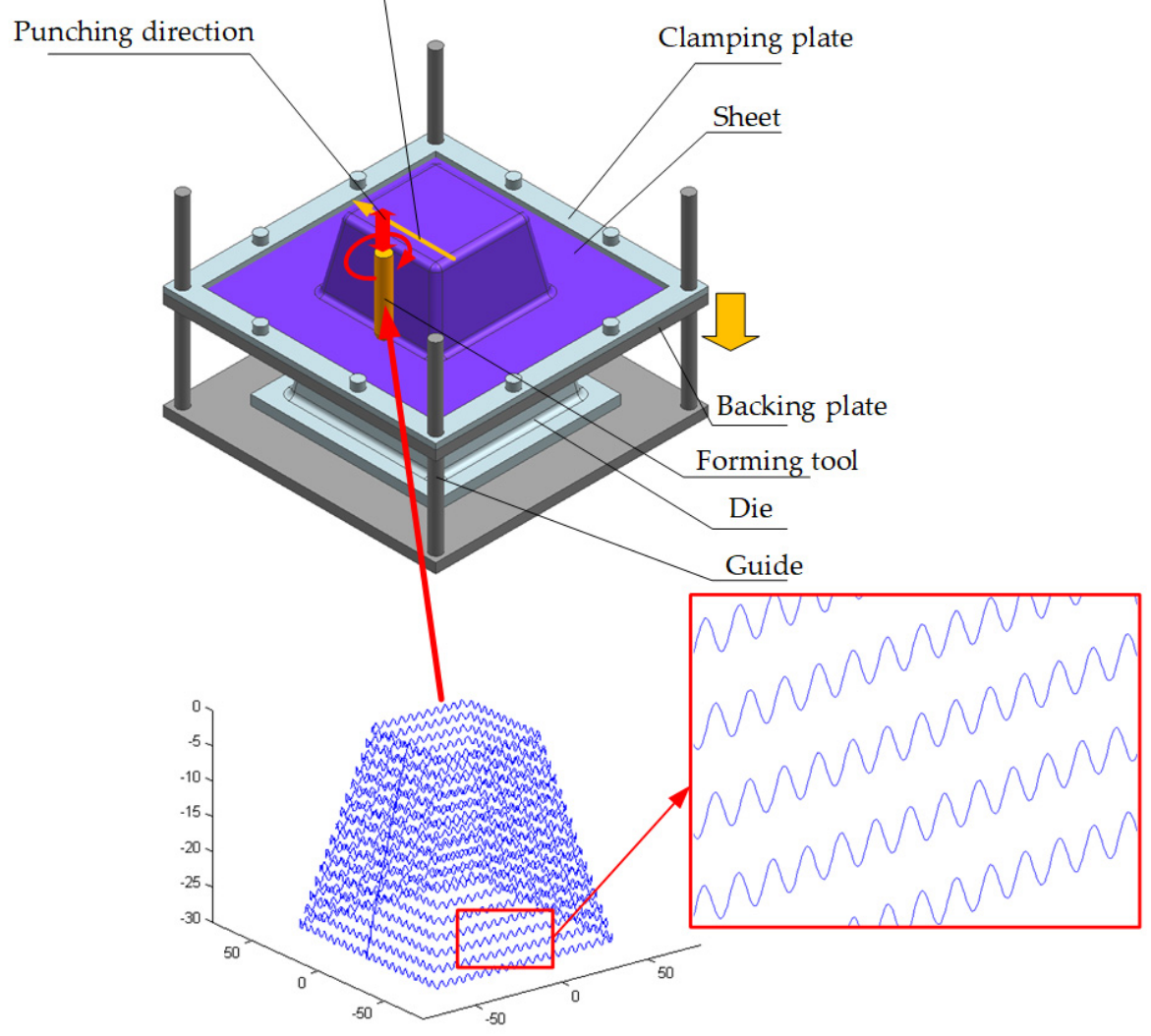

Figure 1. Schematic of incremental sheet punching driven by wave tool path. (a) single point forming; (b) two points forming.

Although, related research on the fatigue performance of ISP is very rare, but it is necessary to understand the influence of wavelength and amplitude on fatigue life. Because the amplitude and wavelength were introduced into the ISP based on the common cutter path, and it was found that different combinations of wavelength and amplitude have obvious influence on the forming performance in the subsequent research, and it is also an important basis for the reasonable selection of process parameters in subsequent research.

In the given paper, based on the full factor experiment, ISP with different wavelengths and amplitudes was used to process the fixed parts, and then the fatigue comparison test is carried out on all fixed parts and unformed sheets [16].

\section{Materials and Methods}

\subsection{Blanks Preparation}

The material of plate used in this Experiment was 6061-T6 with $1 \mathrm{~mm}$ of thickness. Before forming, the sheets of 6061-T6 were cut into $150 \mathrm{~mm} \times 150 \mathrm{~mm}$ blanks. The chemical compositions are shown in Table 1 . The mechanical properties provided by the supplier (CHALCO Shandong Branch, Zibo, China) are listed in Table 2.

Table 1. Chemical compositions of 6061 aluminum alloy sheet (\%, mass fraction).

\begin{tabular}{cccccccc}
\hline $\mathbf{M g}$ & $\mathbf{S i}$ & $\mathbf{C u}$ & $\mathbf{C r}$ & $\mathbf{F e}$ & $\mathbf{Z n}$ & $\mathbf{T i}$ & $\mathbf{A l}$ \\
\hline $0.8-1.2$ & $0.4-0.8$ & $0.15-0.40$ & $0.04-0.35$ & 0.70 & 0.25 & 0.15 & other \\
\hline
\end{tabular}


Table 2. Mechanical property parameters of 6061 aluminum alloy sheet.

\begin{tabular}{cc}
\hline Parameter & Value \\
\hline Yield strength $R_{\mathrm{p} 0.2} / \mathrm{MPa}$ & 240 \\
Tensile strength $R_{\mathrm{m}} / \mathrm{MPa}$ & 290 \\
Elongation $A / \%$ & 6 \\
Hardness $/ \mathrm{HBS}$ & 95 \\
Elastic modulus E/GPa & 68.3 \\
Poisson ratio & 0.33 \\
\hline
\end{tabular}

\subsection{Incremental Sheet Punching}

In this experiment, truncated pyramids were formed by NHJ-1A ISF machine (designed and manufactured by Nanjing University of Aeronautics and Astronautics, Nanjing, China), the trun cated pyramids, shown as Figure 2. The sheets of 6061-T6 were fixed on the support of the NHJ-1A machine. The tool paths for continuous contact tool paths were generated by Siemens NX 12.0 (Siemens PLM Software, Munich, Germany) and converted the continuous contact tool paths to the wave paths through the method shown in [10]. The forming tool with a hemispherical end, made from high-speed steel, was selected. No.46 mechanical oil was used to reduce the coefficient of friction between the tool and the sheet. In order to investgate the influence of wavelength and amplitude on the fatigue life of sheet, based on the previous experience of ISF and ISP [10-12], the process parameters such as tool diameter, z-axis feed rate, feed speed, and hammering angle were set to constant values in this experiment, as shown in Table 3. Wavelength and amplitude were selected as factors to design the full-factor experimental scheme. The specific experimental scheme is given in Table 4.
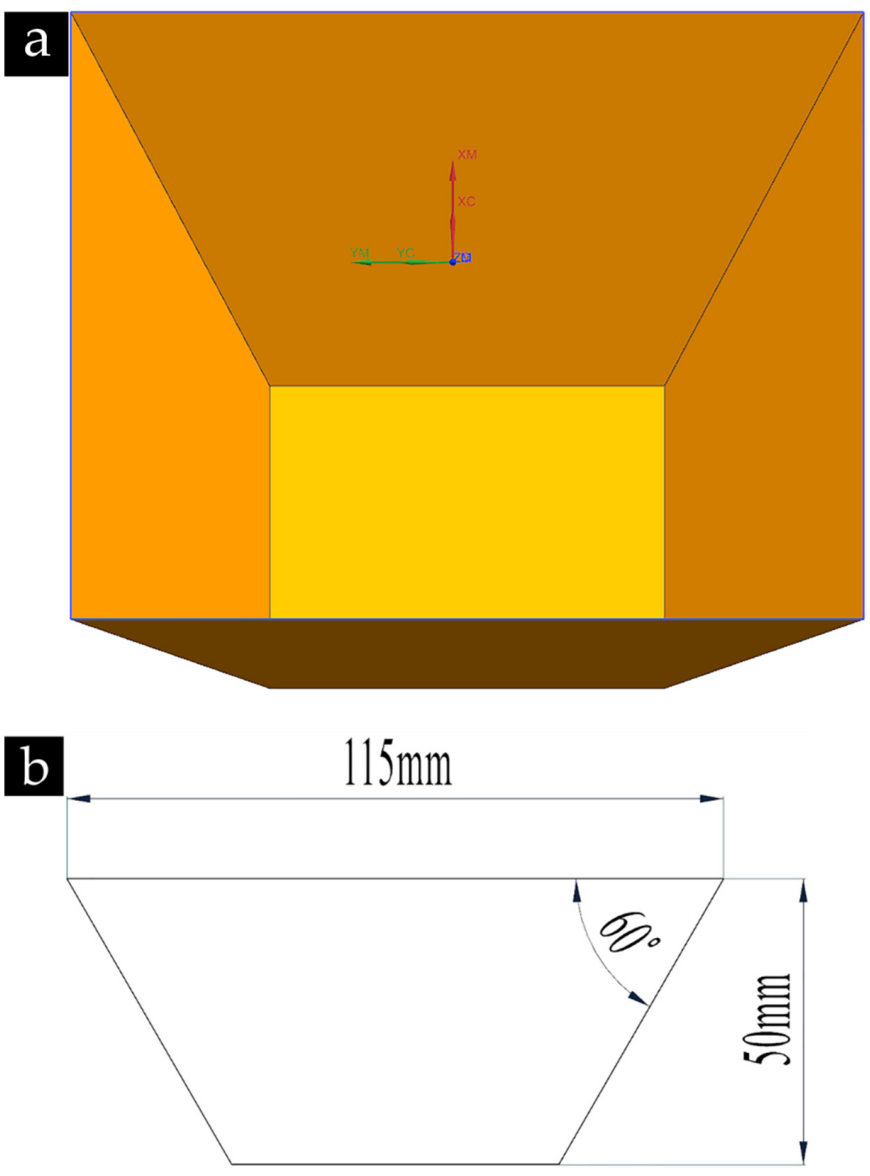

Figure 2. CAD model of the part (a) 3D model of the part; (b) section of the part. 
Table 3. Experimental process parameters.

\begin{tabular}{cccc}
\hline $\begin{array}{c}\text { Tool Diameter } \\
(\mathbf{m m})\end{array}$ & $\begin{array}{c}\text { Vertical Feed } \\
(\mathbf{m m})\end{array}$ & $\begin{array}{c}\text { Feed Speed } \\
(\mathbf{m m} / \mathbf{m i n})\end{array}$ & $\begin{array}{c}\text { Hammer Angle } \\
\left({ }^{\circ}\right)\end{array}$ \\
\hline 10 & 0.5 & 1000 & 90 \\
\hline
\end{tabular}

Table 4. Full factorial experiment plan.

\begin{tabular}{ccc}
\hline & \multicolumn{2}{c}{ Factor } \\
\cline { 2 - 3 } No. & Wavelength(mm) & Amplitude(mm) \\
& 0.2 & 0.4 \\
2 & 0.6 & 0.4 \\
3 & 1.0 & 0.4 \\
4 & 0.2 & 0.8 \\
5 & 0.6 & 0.8 \\
6 & 1.0 & 0.8 \\
7 & 0.2 & 1.2 \\
8 & 0.6 & 1.2 \\
9 & 1.0 & 1.2 \\
\hline
\end{tabular}

\subsection{Fatigue Comparative Test}

To compare the effects of different wavelengths and amplitudes of ISP on the fatigue life of sheet, the fatigue contrast test was carried out on the high-frequency fatigue testing machine (PLG-100, Guanteng Automation, Changchun, China) under uniaxial stresscontrolled tensile conditions at the same stress level [17]. The loading frequency of the testing machine is $100 \mathrm{~Hz}$. To examine the fatigue resistance of the material under a relatively high-stress condition, the maximum stress was chosen as $180 \mathrm{MPa}$, which is $62 \%$ of the tensile strength of 6061-T6. The stress ratio was specified as $R=0.1$. The test stops and automatically records the number of cycles when fatigue failure occurs under cyclic loading. The fatigue contrast test was divided into 9 experimental groups (truncated pyramids) and 1 treatment group (unprocessed 6060-T6 aluminum plate). The fatigue specimen is shown in Figure 3 [18], and the length direction of the specimen is the coincidence direction of the original fiber direction and the processing pattern of the aluminum alloy plate.

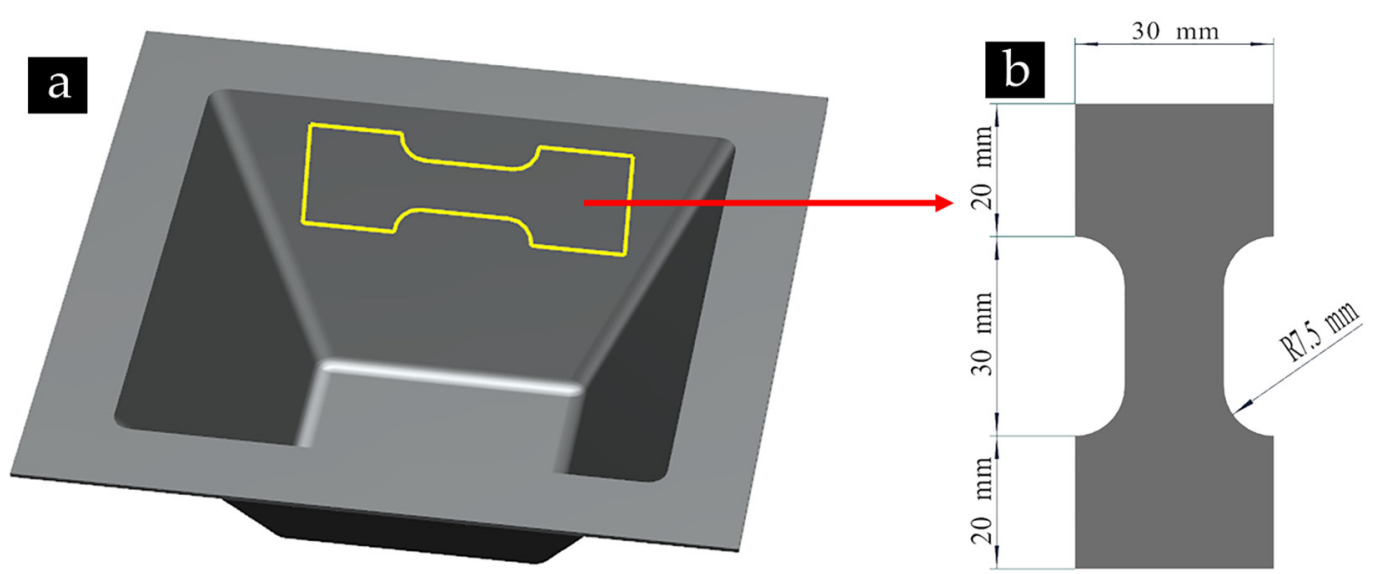

Figure 3. The shape and dimensions of fatigue test specimen. (a) specimen location; (b) fatigue test specimen. 
Given the confidence level $1-\alpha$ and the limit of relative error, the minimum number of specimens can be determined by the following relationship:

$$
n_{\text {min }}=\left(\frac{v t_{1-\alpha}}{\delta}\right)^{2}=\left(\frac{s_{j} t_{1-\alpha}}{\bar{x}_{j} \delta}\right)^{2}
$$

where $n_{\min }$ is minimum number of specimens, $v$ is coefficient of variation, $\delta$ is Limit of relative error, $s_{j}$ and $\bar{x}_{j}$ are the standard deviation and average of subsample $j, t_{1-\alpha}$ can be found by t-distribution table.

In this study, the confidence level was set at 0.95 , and $\delta$ was $5 \%$. According to Equation (1), five specimens were selected for each group of samples [16].

\subsection{Statistical Analysis}

\subsubsection{ANOVA}

ANOVA is a mathematical method that can quantitatively describe the statistical relationship between fatigue life and controllable factors based on experimental data [19]. It can be used to estimate the significance of each control factor on the overall response without the limitation of the number of comparison groups [20]. In this statistical analysis, the SPSS 25.0 (IBM, Armonk, NY, USA) was used to estimate the effects of two independent variables (wavelength and amplitude) on the overall fatigue life.

\subsubsection{Tukey Test}

If the results of ANOVA reject the original assumption, indicating that the mean fatigue life corresponding to different parameters is not equal, and multiple comparisons are needed to further determine which two mean values are significantly different. In this paper, the Tukey test was used for multiple comparisons. Tukey test is mainly used for multiple comparisons with the same number of samples in three groups and more than three groups. An important advantage of the Tukey test is that it is very simple. As long as a value is calculated, all pairs of average differences can be compared. The test principle is illustrated as follows [21]:

Assume $\mu_{1}=\mu_{2}=\cdots=\mu_{k}=\mu$, so there are

$$
P(W)=P\left(\max _{1 \leq j \leq m} \frac{\bar{x}_{j}-\mu}{\hat{\sigma} / \sqrt{n}}-\min _{1 \leq k \leq m} \frac{\bar{x}_{k}-\mu}{\hat{\sigma} / \sqrt{n}} \geq \frac{c}{\hat{\sigma} / \sqrt{n}}\right)
$$

let

$$
q\left(m, f_{e}\right)=\max _{1 \leq j \leq m} \frac{\bar{x}_{j}-\mu}{\hat{\sigma} / \sqrt{n}}-\min _{1 \leq k \leq m} \frac{\bar{x}_{k}-\mu}{\hat{\sigma} / \sqrt{n}}
$$

where $q\left(m, f_{e}\right)$ is the distribution of studentized range with the freedom of $m$ and $f_{e}$. When $P(W)=\alpha$, let

$$
c=q_{1-\alpha}\left(m, f_{e}\right) \hat{\sigma} / \sqrt{n}
$$

where $q_{1-\alpha}\left(m, f_{e}\right)$ is the quantile of $q\left(m, f_{e}\right)$ at confidence level $1-\alpha$.

Comparing the size of $\left|\bar{x}_{j}-\bar{x}_{k}\right|$ and $c$, if $\left|\bar{x}_{j}-\bar{x}_{k}\right| \geq c$, it considers that there is a significant difference between the population means.

In this statistical analysis, this method is used to test the influence of two main effects (wavelength and amplitude) on fatigue life after ANOVA, and the influence degree of the main effect on fatigue life is estimated by confidence interval.

\subsection{3. $t$-Test}

To understand whether the interaction between wavelength and amplitude has a significant effect on the fatigue life of the sheet, and to determine the degree of influence by using the confidence interval, it is necessary to make pairwise comparison between the experimental group and the treatment group. The $t$-test analysis method was used in this study. The principle of $t$-test is to use the theory of student distribution to deduce 
the probability of difference between two means. The $t$-test in this statistical analysis is mainly used to test the significance of the difference between the mean fatigue life of the experimental group and the treatment group, and to estimate the influence of the parameter interaction on the fatigue life of the sheet by the confidence interval. Estimates of impact by confidence intervals are as follows [16]:

$$
\left(\bar{x}_{j}-\bar{x}_{k}\right)-t_{1-\alpha} s_{j k} \sqrt{\frac{1}{n_{j}}+\frac{1}{n_{k}}}<\lg \left[N^{*}\right]_{j}-\lg \left[N^{*}\right]_{k}<\left(\bar{x}_{j}-\bar{x}_{k}\right)+t_{1-\alpha} s_{j k} \sqrt{\frac{1}{n_{j}}+\frac{1}{n_{k}}}
$$

take anti-logarithm

$$
10^{\left(\bar{x}_{j}-\bar{x}_{k}\right)-t_{\gamma} s_{j k} \sqrt{\frac{1}{n_{j}}+\frac{1}{n_{k}}}} \leq \frac{\left[N^{*}\right]_{j}}{\left[N^{*}\right]_{k}} \leq 10^{\left(\bar{x}_{j}-\bar{x}_{k}\right)+t_{\gamma} s_{j k} \sqrt{\frac{1}{n_{j}}+\frac{1}{n_{k}}}}
$$

where $s_{j k}$ is pooled standard deviation. $\left[N^{*}\right]_{j}$ and $\left[N^{*}\right]_{k}$ are the median fatigue life of two populations. For the given significance level $\alpha$, the value of $t_{1-\alpha}$ can be obtained based on the $t$ distribution tables.

In all the above analyses, significant level $\alpha$ was set at $5 \%$, that is, confidence level $(1-\alpha)$ was set at $95 \%$.

\section{Results and Discussion}

\subsection{Results of Fatigue Test}

Partially formed parts and a fractured specimen after fatigue tests are shown in Figures 4 and 5 . Table 5 is the data measured by the group method, according to Table 5 the results of fatigue test are discrete under the same state. Therefore, effective statistics dealing with the large scale of fatigue data will be of great significance to obtain reasonable results. To facilitate observation and statistical analysis, the experimental data are assumed to be lognormal [22]. The logarithms of fatigue lives are shown in Table 6.

Table 5. Results of fatigue life test.

\begin{tabular}{cccccc}
\hline No. & \multicolumn{5}{c}{ Cycle of Fatigue Life $\left(\times \mathbf{1 0}^{\mathbf{5}}\right)$} \\
\hline 1 & 1.897 & 2.019 & 2.804 & 3.053 & 3.675 \\
2 & 1.547 & 2.732 & 2.964 & 5.510 & 8.048 \\
3 & 2.472 & 3.311 & 3.556 & 5.030 & 6.687 \\
4 & 3.504 & 4.096 & 4.323 & 9.476 & 12.325 \\
5 & 1.240 & 3.940 & 4.144 & 4.801 & 12.030 \\
6 & 3.793 & 3.970 & 4.495 & 6.367 & 6.718 \\
7 & 2.730 & 3.740 & 5.249 & 6.758 & 7.943 \\
8 & 2.384 & 2.504 & 3.629 & 4.489 & 8.562 \\
9 & 1.915 & 2.380 & 2.535 & 2.918 & 4.291 \\
$10^{\text {a }}$ & 0.893 & 1.435 & 1.610 & 1.611 & 2.134 \\
\hline
\end{tabular}

a. treatment group.

\begin{tabular}{|c|c|c|c|c|c|c|c|c|c|c|c|c|}
\hline \multirow{2}{*}{ No. } & \multicolumn{10}{|c|}{ Logarithm of Fatigue Life $x_{j i}=\lg N_{j i}$} & \multirow{2}{*}{$p(\%)$} & \multirow{2}{*}{$\mu_{p i}$} \\
\hline & $x_{1 i}$ & $x_{2 i}$ & $x_{3 i}$ & $x_{4 i}$ & $x_{5 i}$ & $x_{6 i}$ & $x_{7 i}$ & $x_{8 i}$ & $x_{9 i}$ & $x_{10 i}{ }^{\mathbf{a}}$ & & \\
\hline 1 & 5.278 & 5.189 & 5.393 & 5.545 & 5.093 & 5.579 & 5.436 & 5.377 & 5.282 & 4.951 & 83.33 & -0.9685 \\
\hline 2 & 5.305 & 5.436 & 5.520 & 5.612 & 5.595 & 5.599 & 5.573 & 5.399 & 5.377 & 5.157 & 66.67 & -0.4313 \\
\hline 3 & 5.448 & 5.472 & 5.551 & 5.636 & 5.617 & 5.653 & 5.720 & 5.560 & 5.404 & 5.207 & 50.00 & 0.0000 \\
\hline 4 & 5.485 & 5.741 & 5.702 & 5.977 & 5.681 & 5.804 & 5.830 & 5.652 & 5.465 & 5.207 & 33.33 & 0.4313 \\
\hline 5 & 5.565 & 5.906 & 5.825 & 6.091 & 6.080 & 5.827 & 5.900 & 5.933 & 5.633 & 5.329 & 16.67 & 0.9685 \\
\hline
\end{tabular}

Table 6. Logarithm of fatigue life.

a. treatment group; $p$ : maternal survival rate; $u_{p i}$ : normal deviation. 

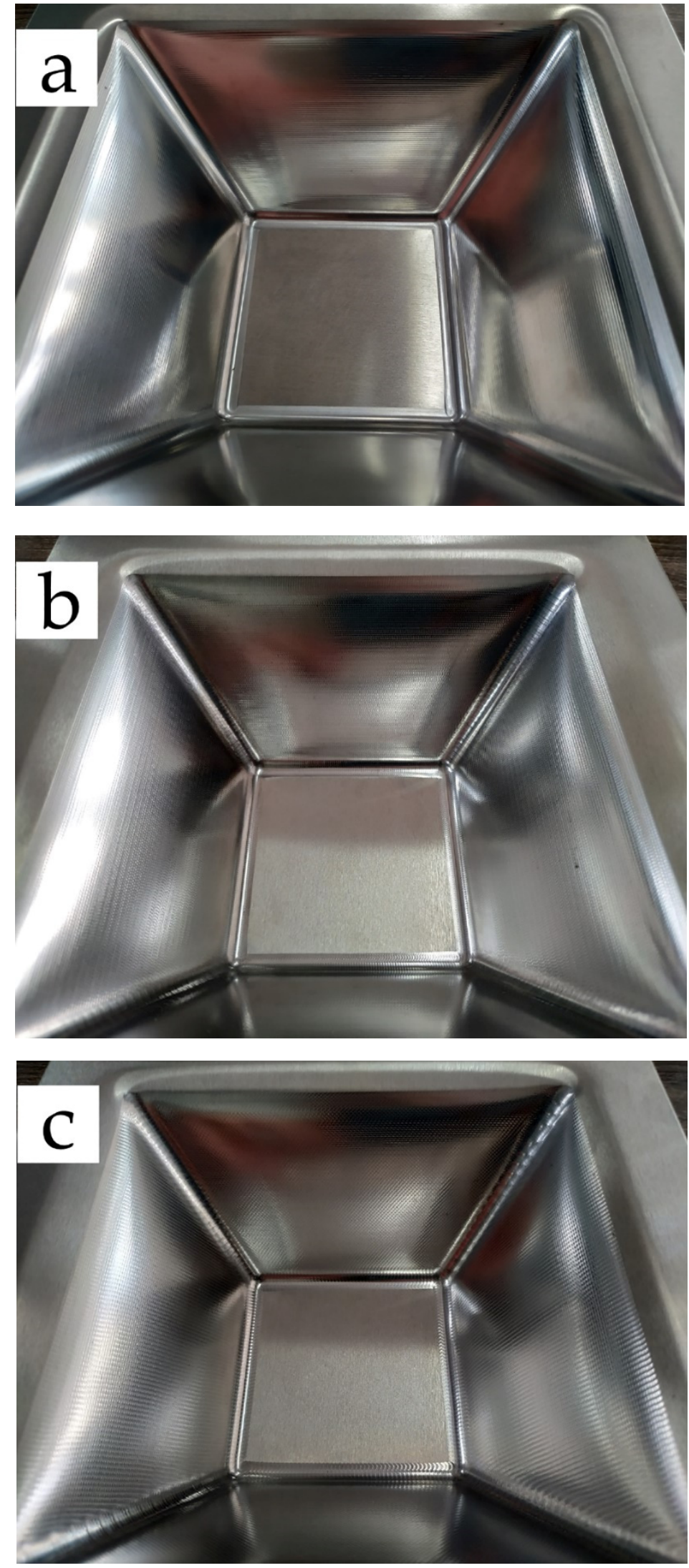

Figure 4. The formed parts in Table 5 (a) formed by wavelength 0.2 and amplitude $0.4 ;(\mathbf{b})$ formed by wavelength 0.6 and amplitude 0.4 ; (c) formed by wavelength 1.0 and amplitude 0.4 . 


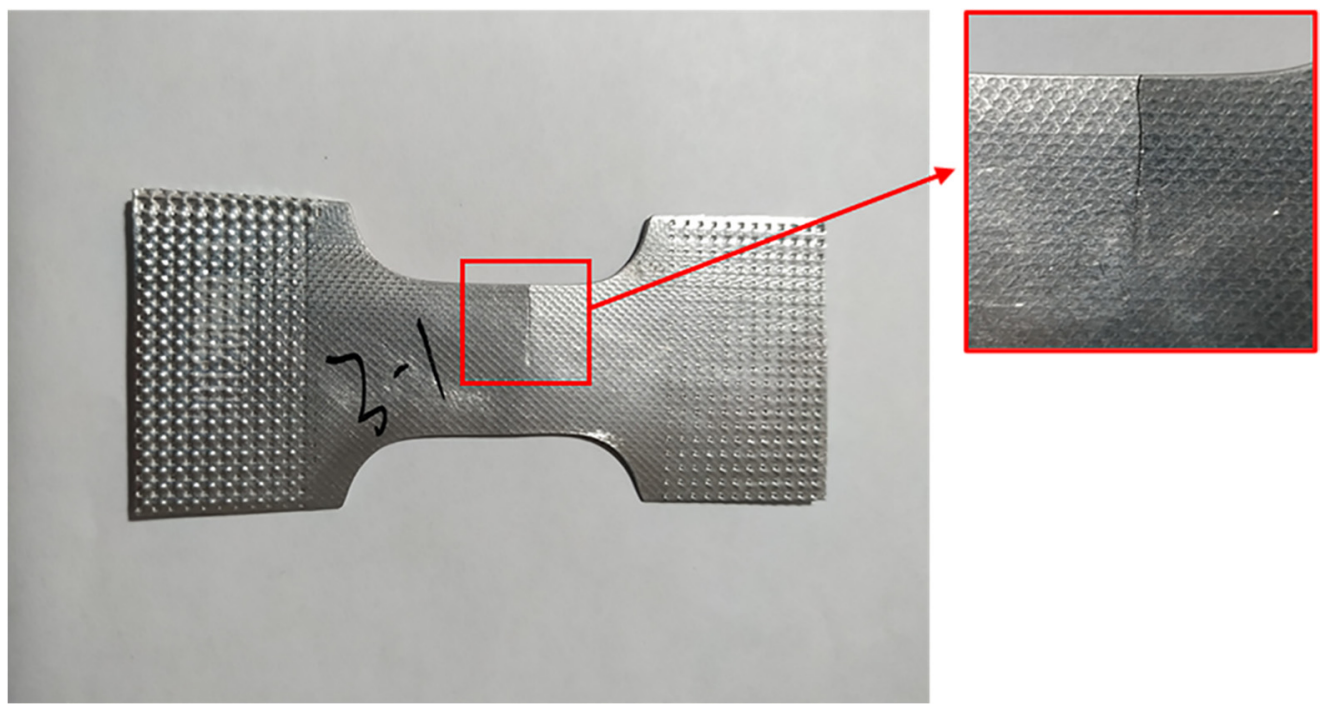

Figure 5. A specimen after fatigue test.

\subsection{Statistical Analysis Results of Fatigue Contrast Test}

\subsubsection{Test of Normality}

Table 7 shows the statistical results of the normality test with different main effects (wavelength and amplitude). The values $P$ of the wavelength, amplitude, and treatment group are more than 0.05 , which means that the fatigue lives of the experimental group and the treatment group were in normal distribution.

Table 7. Normality test results of main effect fatigue life.

\begin{tabular}{ccccc}
\hline Source & Level & $\boldsymbol{r}$ & $\mathbf{d f}$ & $\boldsymbol{p}$ \\
\hline \multirow{3}{*}{ Wavelength } & 0.2 & 0.958 & 15 & 0.666 \\
& 0.6 & 0.984 & 15 & 0.989 \\
& 1.0 & 0.957 & 15 & 0.646 \\
\hline \multirow{3}{*}{ Amplitude } & 0.4 & 0.969 & 15 & 0.849 \\
& 0.8 & 0.889 & 15 & 0.065 \\
Treatment group & 1.2 & 0.929 & 15 & 0.264 \\
\hline
\end{tabular}

\subsubsection{Levene Homogeneity of Variance Test}

The homogeneity of variance test results are shown in Table 8 . The value of $F_{1-\alpha}$ $(s-1, n-s)$ can be obtained based on the F distribution tables. In the condition of this statistic experiment, the value of $F_{0.95}(9,40)$ is 2.12. The results show that the values $W[23,24]$ are all less than 2.12 , and the values $P$ are more than 0.05 , which means that the variance between samples is homogeneity.

Table 8. Test results of homogeneity of variance.

\begin{tabular}{cccccc}
\hline Source & Based on & $\boldsymbol{W}$ & $\mathbf{d f 1}$ & df2 & $\boldsymbol{p}$ \\
\hline \multirow{3}{*}{ Logarithm of Fatigue life } & Mean & 1.011 & 9 & 40 & 0.448 \\
& Median & 0.588 & 9 & 40 & 0.799 \\
& trimmed mean & 0.990 & 9 & 40 & 0.463 \\
\hline
\end{tabular}

df1: Freedom of molecules; df2: Freedom of denominator. 


\subsubsection{Results of ANOVA}

Table 9 shows the statistical results of ANOVA with different main effects (wavelength and amplitude). The values $P$ of the corrected model are less than 0.05 , which means that at least one main factor has a significant effect on the fatigue life of sheet.

Table 9. Results of ANOVA.

\begin{tabular}{cccccc}
\hline Source & Type III Sum of Squares & df & Mean Square & $\boldsymbol{F}$ & $\boldsymbol{p}$ \\
\hline Corrected Model & $1.366^{\mathrm{a}}$ & 9 & 0.152 & 3.448 & 0.003 \\
Wavelength & 0.024 & 2 & 0.012 & 0.272 & 0.763 \\
Amplitude & 0.235 & 2 & 0.117 & 2.667 & 0.082 \\
Wavelength $\times$ amplitude & 0.298 & 4 & 0.074 & 1.690 & 0.171 \\
Error & 1.761 & 40 & 0.044 & & \\
Total & 1544.326 & 50 & & & \\
Corrected Total & 3.127 & 49 & & & \\
\hline
\end{tabular}

a. $\mathrm{R}$ Squared $=0.437$ (Adjusted R Squared $=0.310$ ).

Numerous studies have shown that abilities of fatigue resistance of sample depend on its hardening depth and residual stress state [18]. Driven by wave tool path, ISP tool always imposes concentrated uniform axial forming force on the sheet, resulting in a fairly uniform distribution of compressive residual stresses along the component wall, which might explain the higher fatigue life observed for deformed material as compared to virgin material $[15,25]$. Moreover, due to the wave tool path, the surface strengthening effect similar to shot peening treatment will be produced by tool in the ISP, so that the residual tensile stress on the surface of the sheet is transformed into residual compressive stress, which inhibits the crack opening $[26,27]$ and improves the fatigue life of sheet.

\subsubsection{Results of Tukey Test}

The statistical results of the Tukey test with different wavelengths are shown in Table 10. The results show that all values $P$ are less than 0.05 , which indicates that wavelength has obvious effects on fatigue life as compared to virgin material. Figure 6a shows the comparison results of the fatigue mean between the experimental group and the treatment group under the same amplitude. It is shown that the fatigue lives of the plate with different wavelengths have been significantly improved. Table 11 lists the improvement intervals of the fatigue life of the plate with different wavelengths, and the results are shown in Figure 7a. The trend in the figure indicates that higher values of wavelength lead to the lower improvement of fatigue life, and the maximum improvement of fatigue life was 1.47-5.58 times when wavelength equaled $0.2 \mathrm{~mm}$.

Table 10. Effect of wavelength on fatigue life.

\begin{tabular}{|c|c|c|c|c|c|c|}
\hline \multirow{2}{*}{$\begin{array}{c}\text { (I) } \\
\text { Wavelength }\end{array}$} & \multirow{2}{*}{$\begin{array}{c}(\mathrm{J}) \\
\text { Treatment } \\
\text { Group }\end{array}$} & \multirow{2}{*}{$\begin{array}{c}\text { Mean } \\
\text { Difference } \\
(\mathrm{I}-\mathrm{J})\end{array}$} & \multirow[b]{2}{*}{ Std. Error } & \multirow[b]{2}{*}{$p$} & \multicolumn{2}{|c|}{ 95\% Confidence Interval } \\
\hline & & & & & $\begin{array}{l}\text { Lower } \\
\text { Bound }\end{array}$ & $\begin{array}{l}\text { Upper } \\
\text { Bound }\end{array}$ \\
\hline 0.2 & & $0.45650 *$ & 0.108344 & 0.001 & 0.16609 & 0.74691 \\
\hline 0.6 & Sheet & $0.41204 *$ & 0.108344 & 0.003 & 0.12163 & 0.70245 \\
\hline 1.0 & & $0.40402 *$ & 0.108344 & 0.003 & 0.11362 & 0.69443 \\
\hline
\end{tabular}

Based on observed means.The error term is Mean Square (Error) $=0.044 .{ }^{*}$ The mean difference is significant at the 0.05 level. 

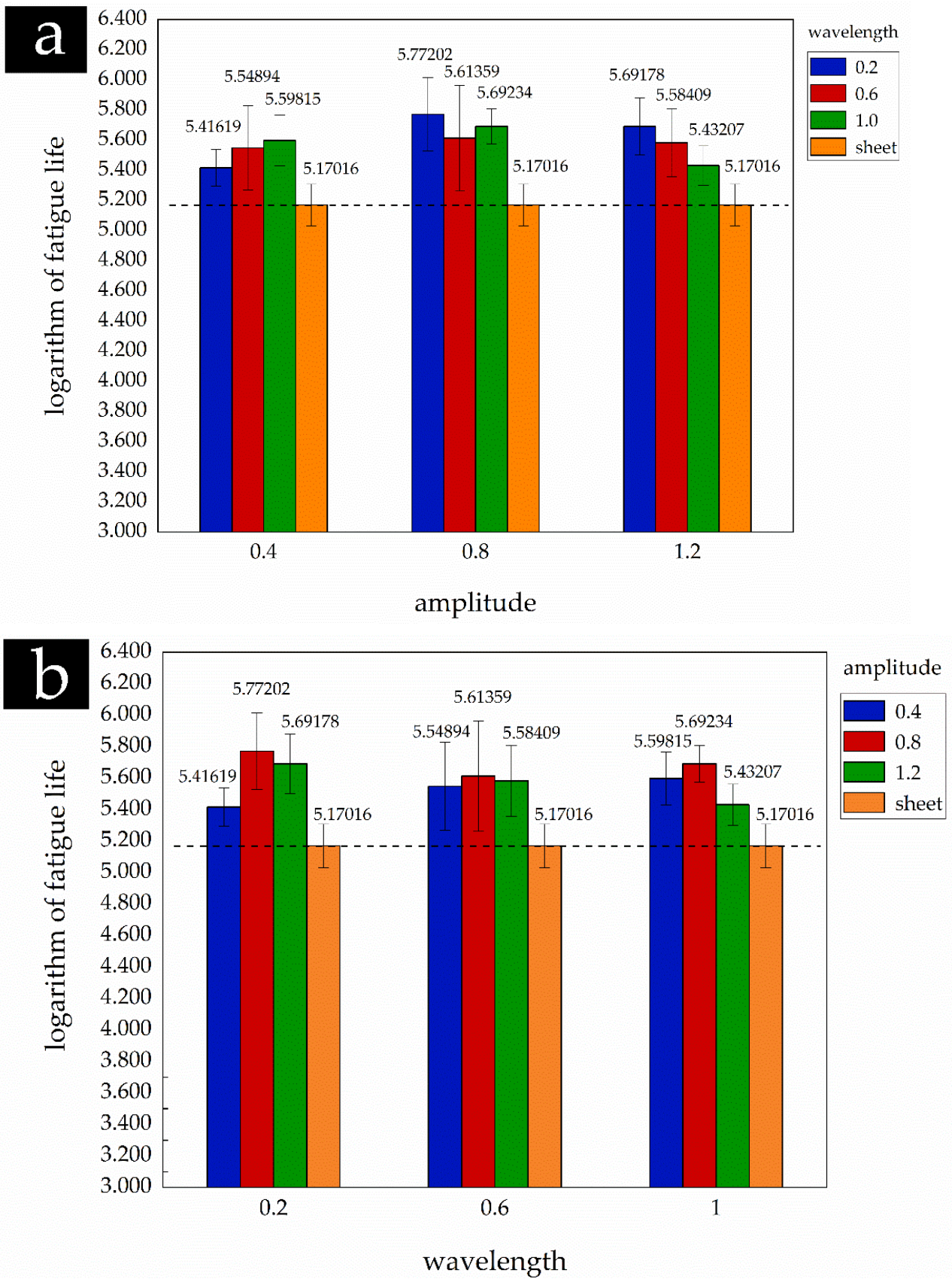

Figure 6. Comparison of mean fatigue life of sub-samples affected by different parameters. (a) affected by wavelength; (b) affected by amplitude.

Table 11. Increasing range of fatigue life by wavelength.

\begin{tabular}{ccc}
\hline Treatment Group & Wavelength & Multiple \\
\hline Sheet & 0.2 & $1.47-5.58$ \\
& 0.6 & $1.32-5.04$ \\
& 1.0 & $1.30-4.95$ \\
\hline
\end{tabular}



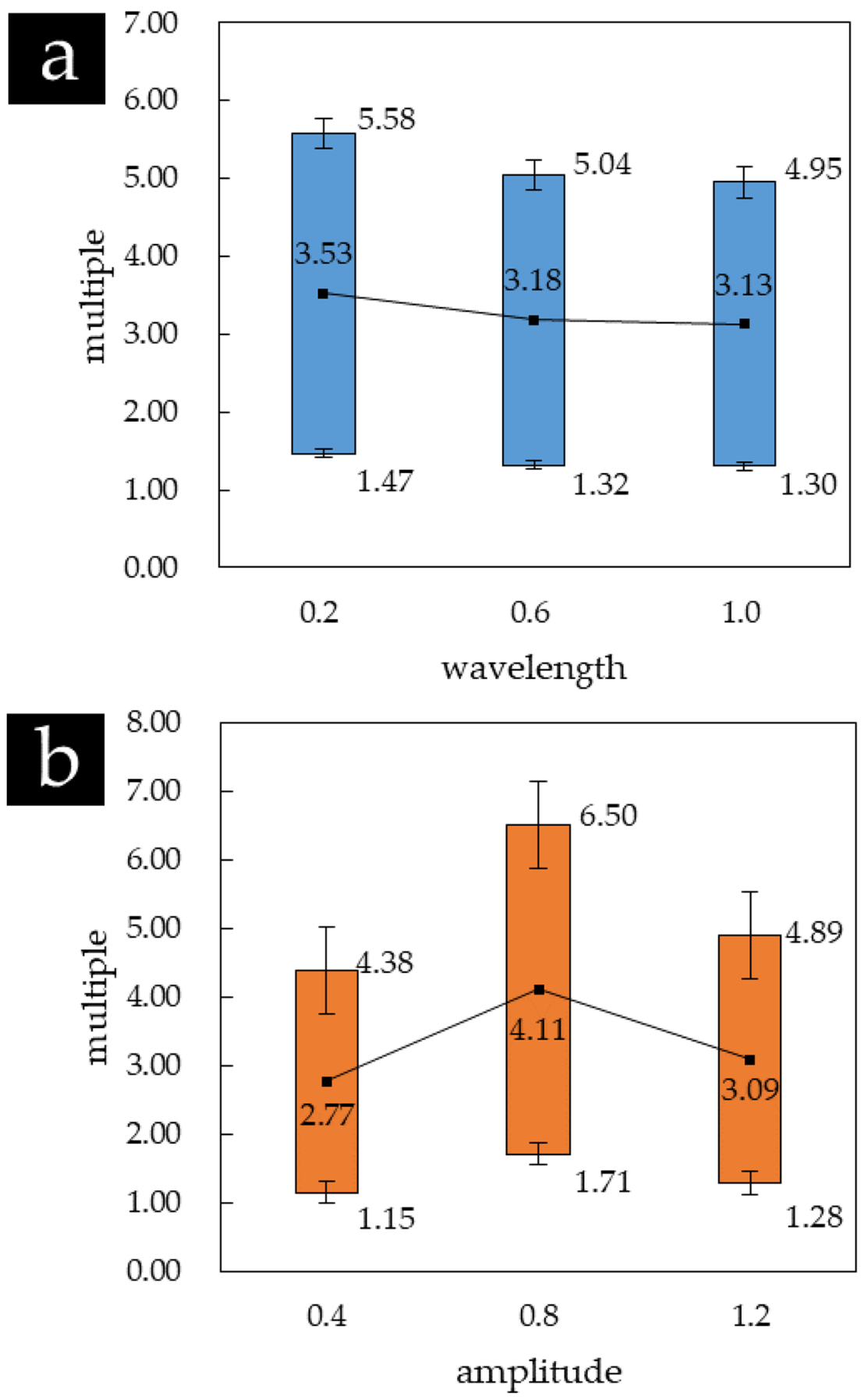

Figure 7. Comparison of creasing range of fatigue life by the main factor. (a) affected by wavelength; (b) affected by amplitude.

It is well known that the fatigue life of sheet depends on the behaviors of crack initiation and propagation [18]. The uneven surface is easy to generate stress concentration to accelerate the initiation and propagation of fatigue cracks; thus. the roughness of specimen surface is one of the factors affecting the fatigue life. The increment of wavelength increases surface roughness [10], therefore, the improvement of fatigue life decreases with the increment of wavelength.

Table 12 shows the statistical results of the Tukey test with different amplitudes. Similar to the Tukey test results of the effect of wavelength on fatigue life, different amplitudes have significant effects on the fatigue life $(p<0.05)$. Figure $6 \mathrm{~b}$ shows that the mean fatigue lives with different amplitudes are significantly improved. The increased intervals of mean 
fatigue life are shown in Table 13, and the results are presented in Figure $7 \mathrm{~b}$. The results can be obtained that the improvement of fatigue life increases with the increment of amplitude when it is less than a certain value (it was equal to $0.8 \mathrm{~mm}$ in this paper), followed by decreasing, and the maximum improvement of fatigue life was 1.71-6.50 times.

Table 12. Effect of amplitude on fatigue life.

\begin{tabular}{ccccccc}
\hline $\begin{array}{c}(\mathbf{I}) \\
\text { Amplitude }\end{array}$ & $\begin{array}{c}(\mathbf{J}) \\
\text { Treatment Group }\end{array}$ & $\begin{array}{c}\text { Mean Difference } \\
(\mathbf{I}-\mathbf{J})\end{array}$ & Std. Error & $p$ & \multicolumn{2}{c}{ 95\% Confidence Interval } \\
\cline { 5 - 7 } & & $0.35093^{*}$ & 0.108344 & 0.012 & 0.06052 & 0.64134 \\
0.8 & \multirow{2}{*}{ Sheet } & $0.52249^{*}$ & 0.108344 & 0.000 & 0.23208 & 0.81289 \\
1.2 & & $0.39915^{*}$ & 0.108344 & 0.004 & 0.10874 & 0.68956 \\
\hline
\end{tabular}

Based on observed means. The error term is Mean Square(Error) $=0.044 .{ }^{*}$. The mean difference is significant at the 0.05 level.

Table 13. Increasing range of fatigue life by amplitude.

\begin{tabular}{ccc}
\hline Treatment Group & Amplitude & Multiple \\
\hline Sheet & 0.4 & $1.15-4.38$ \\
- & 0.8 & $1.71-6.50$ \\
- & 1.2 & $1.28-4.89$ \\
\hline
\end{tabular}

In the process of shot peening strengthening, the projectile velocity is a factor affecting the magnitude of surface residual stress. The increment of projectile velocity shortens the impact interval time, and the residual compressive stress on the strengthened surface increases first and then decreases [28]. Therefore, the fatigue life shows the same trend as residual stress. Since the contact time between tool and plate increases with the increment of amplitude, similar to the shot peening strengthening, the influence of amplitude on fatigue life is the same as projectile velocity.

\subsubsection{Results of $t$-Test}

The statistical results of the $t$-test by SPSS software are presented in Table 14 shows that values $P$ were less than 0.05 , which indicates that the interaction of parameters had a significant impact on the fatigue life of sheet. The influence area of the interaction of parameters on fatigue life can be estimated by the confidence interval, as shown in Table 15 and Figure 8, the results indicate that the maximum improvement of fatigue life with interaction was 2.05-7.79 times when wavelength equaled $0.2 \mathrm{~mm}$ and the amplitude equaled 0.8 , which correspond to the main effect on fatigue life. Figure 8 also shows that the influence of wavelength and amplitude on the fatigue life of sheet metal is also applicable to the interaction of parameters.

Table 14. Results of $t$-test.

\begin{tabular}{|c|c|c|c|c|c|}
\hline \multirow{2}{*}{$\begin{array}{l}\text { Treatment } \\
\text { Group }\end{array}$} & \multirow{2}{*}{$\begin{array}{l}\text { Experimental } \\
\text { Group }\end{array}$} & \multirow{2}{*}{$t$} & \multirow{2}{*}{$p$} & \multicolumn{2}{|c|}{$\begin{array}{c}95 \% \text { Confidence Interval of } \\
\text { the Difference }\end{array}$} \\
\hline & & & & Lower & Upper \\
\hline Sheet & 1 & 2.988 & 0.017 & 0.056151 & 0.435908 \\
\hline- & 2 & 2.718 & 0.026 & 0.057470 & 0.700078 \\
\hline - & 3 & 4.403 & 0.002 & 0.203855 & 0.652125 \\
\hline - & 4 & 4.792 & 0.001 & 0.312213 & 0.891508 \\
\hline \multirow[t]{2}{*}{-} & 5 & 2.628 & 0.030 & 0.054273 & 0.832573 \\
\hline & 6 & 6.474 & 0.000 & 0.336187 & 0.708156 \\
\hline- & 7 & 4.985 & 0.001 & 0.280337 & 0.762901 \\
\hline - & 8 & 3.498 & 0.008 & 0.141032 & 0.686822 \\
\hline - & 9 & 3.088 & 0.015 & 0.066308 & 0.457512 \\
\hline
\end{tabular}


Table 15. Comparison of creasing range of fatigue life by interaction.

\begin{tabular}{ccc}
\hline $\begin{array}{c}\text { Treatment } \\
\text { Group }\end{array}$ & $\begin{array}{c}\text { Experimental } \\
\text { Group }\end{array}$ & Multiple \\
\hline Sheet & 1 & $1.14-2.73$ \\
- & 2 & $1.14-5.01$ \\
- & 3 & $1.60-4.49$ \\
- & 4 & $2.05-7.79$ \\
- & 5 & $1.13-6.80$ \\
- & 6 & $2.17-5.11$ \\
- & 7 & $1.91-5.79$ \\
- & 8 & $1.38-4.86$ \\
- & 9 & $1.16-2.87$ \\
\hline
\end{tabular}

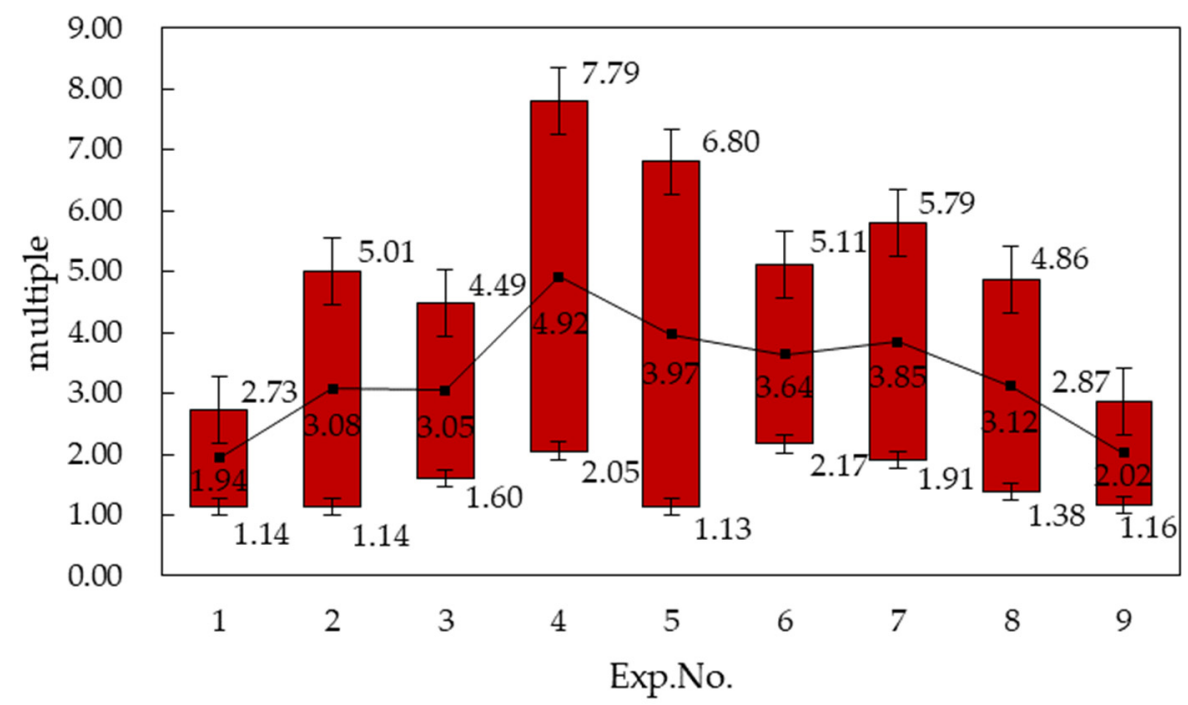

Figure 8. Comparison of creasing range of fatigue life by interaction.

Since ISP has the characteristics of processing complex and diverse parts, it has been commonly used in sheet metal forming fields such as automobile and aerospace [29]. The fatigue performance plays a decisive role in the failure of mechanical products, e.g.,the fatigue performance of the material of the aircraft fuselage affects the life accuracy of the aircraft structure and the life extension measures under the action of dynamic and static loads [22,30]. Therefore, evaluating the fatigue performance of ISP machining parts and introducing the fatigue strength design play a vitally important role in improving the fatigue life of parts. In this study, the influence of wavelength and amplitude on the fatigue performance of sheet was determined through the fatigue contrast test, and the optimum parameter combination for improving fatigue life was confirmed in a certain range. The test results may be worthwhile for determining the fatigue safety factor for the ISP parts' design and manufacture.

\section{Conclusions}

Based on the small sample statistical analysis theory, the influence of different process parameters (wavelength and amplitude) of ISP on the fatigue life of 6061-T6 sheet material was studied by fatigue comparison test in this paper. The main conclusions are summarized as follows:

(1) ISP formed parts may have greater fatigue life under cyclic tension as compared to the virgin material. The improvement of fatigue life decreases with the increase of wavelength and increases with the increment of amplitude when it is less than a certain value, followed by decreasing. 
(2) Under the given parameter values, the maximum improvement of fatigue life was 1.47-5.58 times when wavelength equaled $0.2 \mathrm{~mm}$ and was 1.71-6.50 times when amplitude equaled $0.8 \mathrm{~mm}$.

(3) The maximum improvement of fatigue life with interaction was 2.05-7.79 times when wavelength equaled $0.2 \mathrm{~mm}$ and the amplitude equaled $0.8 \mathrm{~mm}$.

In the future, the influence of different parameters on the fatigue limit of the plate will be studied by establishing the S-N curve of the parts by ISP, and the macro-mechanism and micro-mechanism of the impact of ISP on the fatigue life of the plate will be deeply understood by residual stress analysis and fracture analysis.

Author Contributions: Conceptualization, J.W.; methodology, J.W. and X.W.; software, X.W.; validation, X.W., Y.W. and M.W.; formal analysis, X.W., Y.W. and M.W.; investigation, X.W.; resources, J.W.; data curation, X.W., Y.W. and M.W.; writing-original draft preparation, J.W. and X.W.; writingreview and editing, J.W. and X.W.; visualization, X.W.; supervision, J.W.; project administration, J.W.; funding acquisition, J.W. All authors have read and agreed to the published version of the manuscript.

Funding: This research was funded by Key R\&D projects of Shandong Province, grant number 2019GGX102023.

Institutional Review Board Statement: Not applicable.

Informed Consent Statement: Not applicable.

Data Availability Statement: The data presented in this study are available in this article.

Acknowledgments: Thanks to the China United Test and Evaluation (Qingdao) Co.,LTD (Qingdao, China) for their support in conducting the experiment.

Conflicts of Interest: The authors declare no conflict of interest.

\section{References}

1. Jeswiet, J.; Adams, D.; Doolan, M.; McAnulty, T.; Gupta, P. Single point and asymmetric incremental forming. Adv. Manuf. 2015, 3, 253-262. [CrossRef]

2. Jeswiet, J.; Micari, F.; Hirt, G.; Bramley, A.; Duflou, J.; Allwood, J. Asymmetric Single Point Incremental Forming of Sheet Metal. CIRP Ann. 2005, 54, 88-114. [CrossRef]

3. Wang, J.; Jiang, H.S.; Long, T.; Wang, B.P. Study on experimental method of measuring forming limit diagram in incremental sheet forming. Forg. Stamp. Technol. 2013, 38, 34-36, 39.

4. Zhang, S.; Jin, W.; Shi, J.; Zhang, X.; Zhang, Z. Incremental forming performance of retiary sheet metal. Forg. Stamp. Technol. 2016, $41,48-52,88$.

5. Schafer, T.; Schraft, R.D. Incremental sheet metal forming by industrial robots. Rapid Prototyp. J. 2005, 11, 278-286. [CrossRef]

6. Vihtonen, L.; Puzik, A.; Katajarinne, T. Comparing two robot assisted incremental forming methods: Incremental forming by pressing and incremental hammering. Int. J. Mater. Form. 2008, 1, 1207-1210. [CrossRef]

7. Luo, Y.; He, K.; Du, R. A new sheet metal forming system based on the incremental punching, part 1: Modeling and simulation. Int. J. Adv. Manuf. Technol. 2010, 51, 481-491. [CrossRef]

8. Luo, Y.; He, K.; Du, R. A new sheet metal forming system based on incremental punching, part 2: Machine building and experiment results. Int. J. Adv. Manuf. Technol. 2010, 51, 493-506. [CrossRef]

9. Sedighi, M.; Riahi, M.; Asgari, A. An analytical method for prediction of the incremental sheet metal punching process. Int. J. Adv. Manuf. Technol. 2015, 78, 231-238. [CrossRef]

10. Wang, J.; Li, L.; Jiang, H.; Zhang, Z.; Zhang, S. Incremental sheet punching on the base of sinusoidal tool path. Int. J. Adv. Manuf. Technol. 2017, 89, 3527-3534. [CrossRef]

11. Zhang, Z.; Jin, W.; Li, L.; Jiang, H.; Bo, G.; Gao, S. Research on the method of motion trajectory of tool-head in incrementally pressing forming. Forg. Stamp. Technol. 2015, 40, 70-73.

12. Jiang, H.; Xu, W.; Zhang, Z.; Jin, W.; Li, L.; Sun, S. Study on incremental punching time driven by wave tool path for sheet metal. Forg. Stamp. Technol. 2017, 42, 89-93.

13. She, J.; Zhang, A. Research on Residual Stress of Revolving Type Metal Sheet Incremental Forming Parts. New Technol. New Process 2013, 1, 40-44.

14. Agrawal, A.; Ziegert, J.; Smith, S.; Woody, B.; Cao, J. Study of Dimensional Repeatability and Fatigue Life for Deformation Machining Bending Mode. J. Manuf. Sci. Eng. 2012, 134, 61009. [CrossRef]

15. Xu, R.; Shi, X.; Xu, D.; Malhotra, R.; Cao, J. A preliminary study on the fatigue behavior of sheet metal parts formed with accumulative-double-sided incremental forming. Manuf. Lett. 2014, 2, 8-11. [CrossRef]

16. Zhentong, G. Fatigue Application Statistics; National Defense Industry Press: Beijing, China, 1986; pp. $288-336$. 
17. Zhang, L.; Hou, Y.W. Effect of Plastic Deformation on Fatigue Life of 6061 Aluminum Alloy. Alum. Fabr. 2013, 2, $21-25$.

18. Subcommittee E08.05 on Cyclic Deformation and Fatigue Crack Formation. ASTM E466-2007, Standard Practice for Conducting Force Controlled Constant Amplitude Axial Fatigue Tests of Metallic Materials; American Society for Testing and Materials: West Conshohocken, PA, USA, 2007.

19. Jing, J.N.; Dong, L.H.; Wang, H.D.; Jin, G. Influences of Vacuum Ion-nitriding on Bending Fatigue Behaviors of $42 \mathrm{CrMo} 4$ Steel: Experiment Verification, Numerical Analysis and Statistical Approach. Int. J. Fatigue 2020, 145, 106104. [CrossRef]

20. Shaw, R.G.; Mitchellolds, T. Anova for Unbalanced Data-An Overview. Ecology 1995, 74, 1638-1645. [CrossRef]

21. Cai, L.; Lv, W. Segmented Testing of Improved Time Series Stationarity Test Based on Tukey. Stat. Decis. 2018, 34, 26-29.

22. Zhang, B.; Zhen-Zhou, L.U. Reliability test of fatigue life of LY12 alloy sheet under low-energy impact loads. Exp. Technol. Manag. 2007, 10, 219-222.

23. Cong, C.; Hua, F. Levene Homogeneity of Variance Test. Chin. J. Health Stat. 2005, 6, 408-420.

24. Brown, M.B.; Forsythe, A.B. Robust Tests for the Equality of Variances. J. Am. Stat. Assoc. 1974, 69, 364-367. [CrossRef]

25. Wang, X.L.; Wang, J.; Zhou, P.; Liu, Q. Effects of Wavelength on Incremental Pressing Forming of Sheet Metal. J. Netshape Form. Eng. 2017, 9, 98-101.

26. Mattson, R.L.; Coleman, W.S., Jr. Effect of Shot-Peening Variables and Residual Stresses on the Fatigue Life of Leaf-Spring Specimens. SAE Trans. 1954, 62, 546-556.

27. Scuracchio, B.G.; Lima, N.B.d.; Schön, C.G. Role of residual stresses induced by double peening on fatigue durability of automotive leaf springs. Mater. Des. 2013, 47, 672-676. [CrossRef]

28. Wang, J.; Zhang, Z.Y.; Fang, X. Effect of Diameter and Velocity of Shooting Pellet on the Distribution Residual Stress of Shot Peening. J. Mater. Sci. Eng. 2013, 31, 588-591, 626.

29. Li, Y.; Chen, X.; Li, F.; Sun, J.; Li, J.; Zhao, G. Research Development on Incremental Sheet Metal Forming Process. J. Netshape Form. Eng. 2017, 9, 1-9.

30. Chen, Y.; Huang, Y.; Xue, C.; Hong, J. VIC-3D Static Analysis and Fatigue Test of Aeronautical Aluminum Alloy 2024. Nonferrous Met. Eng. 2016, 6, 35-39, 67. 